\title{
Microstructure and Mechanical Properties of Squeeze Casting Quasicrystal Reinforced AZ91D Magnesium Matrix Composites
}

\author{
Yang Ling, Hou Hua, Zhao Yuhong, Yang Xiaomin
}

North University of China, Taiyuan 030051, China

\begin{abstract}
To improve the mechanical properties of AZ91D alloy, a squeeze casting process was employed to fabricate AZ91D magnesium matrix composites reinforced with stable icosahedral quasicrystal particles which were introduced as $\mathrm{Mg}-\mathrm{Zn}-\mathrm{Y}$ quasicrystal master alloy. The effects of quasicrystal master alloy content on the microstructure and mechanical properties of the composites were investigated. The results show that the squeeze casting process is an effective method to refine grain size. The composites comprise $\alpha$ - Mg matrix, $\beta$ - $\mathrm{Mg}_{17} \mathrm{Al}_{12}$ phases that disperse on grain boundaries and $\mathrm{Mg}_{3} \mathrm{Zn}_{6} \mathrm{Y}$ quasicrystal particles. A stable interface between the quasicrystal particles and the $\mathrm{Mg}$ matrix is observed. The composite exhibits the maximum ultimate tensile strength of 194.3 MPa and the maximum elongation of $9.2 \%$, when the mass fraction of quasicrystal master alloy is $5 \%$. The reinforcement mechanism is concluded as fine-grain strengthening and quasicrystal particle strengthening.
\end{abstract}

Key words: magnesium matrix composites; squeeze casting; quasicrystal; microstructure; mechanical property

Magnesium matrix composites have attracted increasing attention for application requiring high strength, high stiffness and particular thermal properties. However, the application of the magnesium matrix is restricted due to low wettability between reinforcements and the matrix. So it is necessary to solve the problems by introducing a new reinforcement or adopting a new preparation technique. The properties of the composites mostly depend on the content of reinforcement and the fabrication method of the composites. Recently, most studies focus on ceramic particles reinforced magnesium matrix composites ${ }^{[1-3]}$, but few on quasicrystal reinforced magnesium matrix composites. Quasicrystals have many unique properties such as high hardness, high strength, high thermal stability and low interface energy attributed to their quasiperiodic lattice structure $^{[4-6]}$.

Among the processing methods for fabricating magnesium matrix composites, squeeze casting is one of the most cost-effective methods, which leads to microstructure refinement and alleviation of casting defects due to the abrupt heat transfer and squeezing-pressure effect. This process is easily adopted to conventional die-casting devices and is being increasingly used as a practically effective method to produce more densified products ${ }^{[7,8]}$. Although most studies have been carried out on the microstructure and properties of squeeze casting magnesium alloys and magnesium matrix composites ${ }^{[9-12]}$, very few investigations have been focused on squeeze casting quasicrystal reinforced magnesium matrix composites until now.

The present study intends to enhance mechanical properties by preparing quasicrystal reinforced AZ91D magnesium matrix composites by squeeze casting process. The main objective of the present work is to get a more enhanced understanding of the effect of quasicrystal master alloy content on microstructure and mechanical properties

$\overline{\text { Received date: August 20, } 2015}$

Foundation item: National Natural Science Foundation of China (51204147, 51274175); the International Cooperation Program from the Ministry of Science and Technology of China (2011DFA50520, 2014DFA50320); the Foundation for Graduate Students of Shanxi Province (20123088)

Corresponding author: Yang Ling, Ph. D., Lecturer, College of Materials Science and Engineering, North University of China, Taiyuan 030051, P. R. China, Tel: 0086-351-3945988, E-mail: yangling19810128@163.com 
of the composites. High properties of composites can be obtained by optimizing the content of $\mathrm{Mg}-\mathrm{Zn}-\mathrm{Y}$ quasicrystal master alloy and the squeeze casting process, which has great theoretical and practical significance to promote rapid development and wide application for highstrength and heat-resistant magnesium matrix composites.

\section{Experiment}

The nominal composition of AZ91D alloy is 8.9Al, 0.9Zn, $0.3 \mathrm{Mn}$ and balance of $\mathrm{Mg}(\mathrm{wt} \%)$. The composition of quasicrystal master alloy is $\mathrm{Mg}-45 \mathrm{Zn}-10 \mathrm{Y}$ (wt\%) and the content of quasicrystal master alloy is $0,3,5,7$ and 10. After melting the AZ91D alloy at $700{ }^{\circ} \mathrm{C}$ for $15 \mathrm{~min}$, quasicrystal containing $\mathrm{Mg}-45 \mathrm{Zn}-10 \mathrm{Y}$ alloy was added into melts and the melts were held at the same temperature for homogenization. After pouring the melts directly into a preheated steel die and the composite ingots were prepared by squeeze casting. The applied pressure was $100 \mathrm{MPa}$, the die preheating temperature and pouring temperature were 200 and $700{ }^{\circ} \mathrm{C}$, respectively. Squeeze pressure was applied to the casting within $10 \mathrm{~s}$ of pouring and the duration of applied pressure was $20 \mathrm{~s}$.

Microstructure observations were carried out by optical microscopy (OM) and scanning electron microscopy (SEM). The specimens for OM and SEM were ground, polished and etched with a solution of nitric acid $(4 \mathrm{~mL})$ and ethanol $(96$ $\mathrm{mL}$ ) to investigate morphological characteristics of grains, distribution of strengthening phase and interfacial structure between the strengthening phase and the matrix. Phase identifications were performed by D/Max-RB X-ray diffractometer (XRD) using monochromatic $\mathrm{Cu} \quad \mathrm{K} \alpha$ radiation and JEM-2010 transmission electron microscopy (TEM). Microchemical examination was performed by energy dispersive spectrometer (EDS) equipped on SEM. The mechanical properties of the squeeze casting composites were evaluated by a tensile test at ambient temperature with a tensile rate of $0.5 \mathrm{~mm} / \mathrm{min}$ on CMT5105 electronic universal testing machine using cylindrical test specimens machined from the squeeze cast samples. The gauge length and the diameter of the tensile specimens were $25 \mathrm{~mm}$ and $5 \mathrm{~mm}$, respectively.

\section{Results and Discussion}

\subsection{Microstructure observation}

The X-ray diffraction patterns of AZ91D alloy and quasicrystal reinforced AZ91D matrix composites are displayed in Fig.1. The result of X-ray diffraction pattern of AZ91D alloy indicates that it consists of $\alpha-\mathrm{Mg}$ and $\beta$ - $\mathrm{Mg}_{17} \mathrm{Al}_{12}$. According to Fig.1b, it can be found that with the introducing of quasicrystal master alloy, the composite mainly consists of $\alpha-\mathrm{Mg}, \quad \beta-\mathrm{Mg}_{17} \mathrm{Al}_{12}$ and $\mathrm{Mg}_{3} \mathrm{Zn}_{6} \mathrm{Y}$ icosahedral quasicrystal phase (I-phase).

Fig. 2 shows the microstructures of the composites with different contents of quasicrystal master alloy, which mainly consist of $\alpha-\mathrm{Mg}$ matrix, $\beta-\mathrm{Mg}_{17} \mathrm{Al}_{12}$ phase surrounding the boundaries and $\mathrm{Mg}_{3} \mathrm{Zn}_{6} \mathrm{Y}$ icosahedral quasicrystal particles. The microstructure of AZ91D alloy comprises coarse $\alpha-\mathrm{Mg}$ grains and $\beta-\mathrm{Mg}_{17} \mathrm{Al}_{12}$ phase which is concentrated along the boundaries in network as shown in Fig.2a. Fig.2b shows the microstructure of the composite with $3 \%$ quasicrystal master alloy. It can be seen that the grain size is slightly finer than that of AZ91D alloy and the microstructure exhibits distinct regions of fine and coarse structure (Bi-modal structure $)^{[13,14]}$, in which the fine grains are formed in the late-stage of solidification attributed to high cooling rate for remaining melts between the large initial grains. The microstructure of the composite with $5 \%$ quasicrystal master alloy is shown in Fig.2c. It can be found that a few of $\mathrm{Mg}_{3} \mathrm{Zn}_{6} \mathrm{Y}$ quasicrystal particles exist in the composite which contributes to heterogeneous nucleation during the subsequent solidification of AZ91D alloy. So fine grain sizes of $\alpha-\mathrm{Mg}$ and $\beta-\mathrm{Mg}_{17} \mathrm{Al}_{12}$ are obtained. $\mathrm{Bi}$-modal structure is also be found with further increasing the content of quasicrystal master alloy to $7 \%$ and $10 \%$ as shown in Fig.2d and Fig.2e. The formation of large grain sizes is attributed to recalescence phenomenon during solidification, while the small grain size is ascribed to larger constituent undercooling caused by solute segregation, especially when the content of quasicrystal master alloy is $10 \%$.
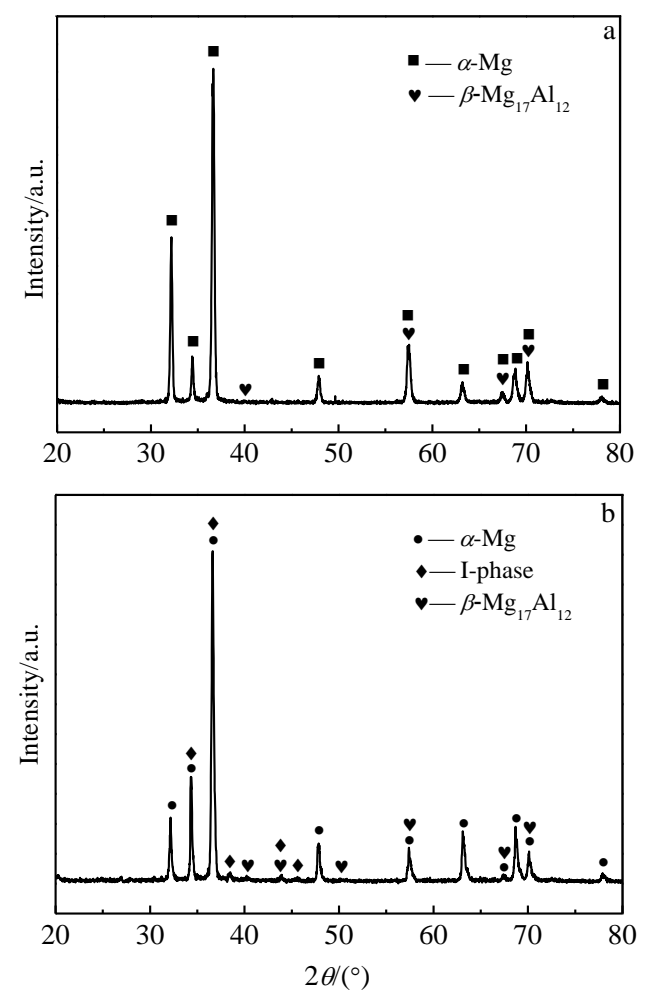

Fig.1 XRD patterns of AZ91D alloy (a) and composite sample with $10 \%$ quasicrystal master alloy (b) 


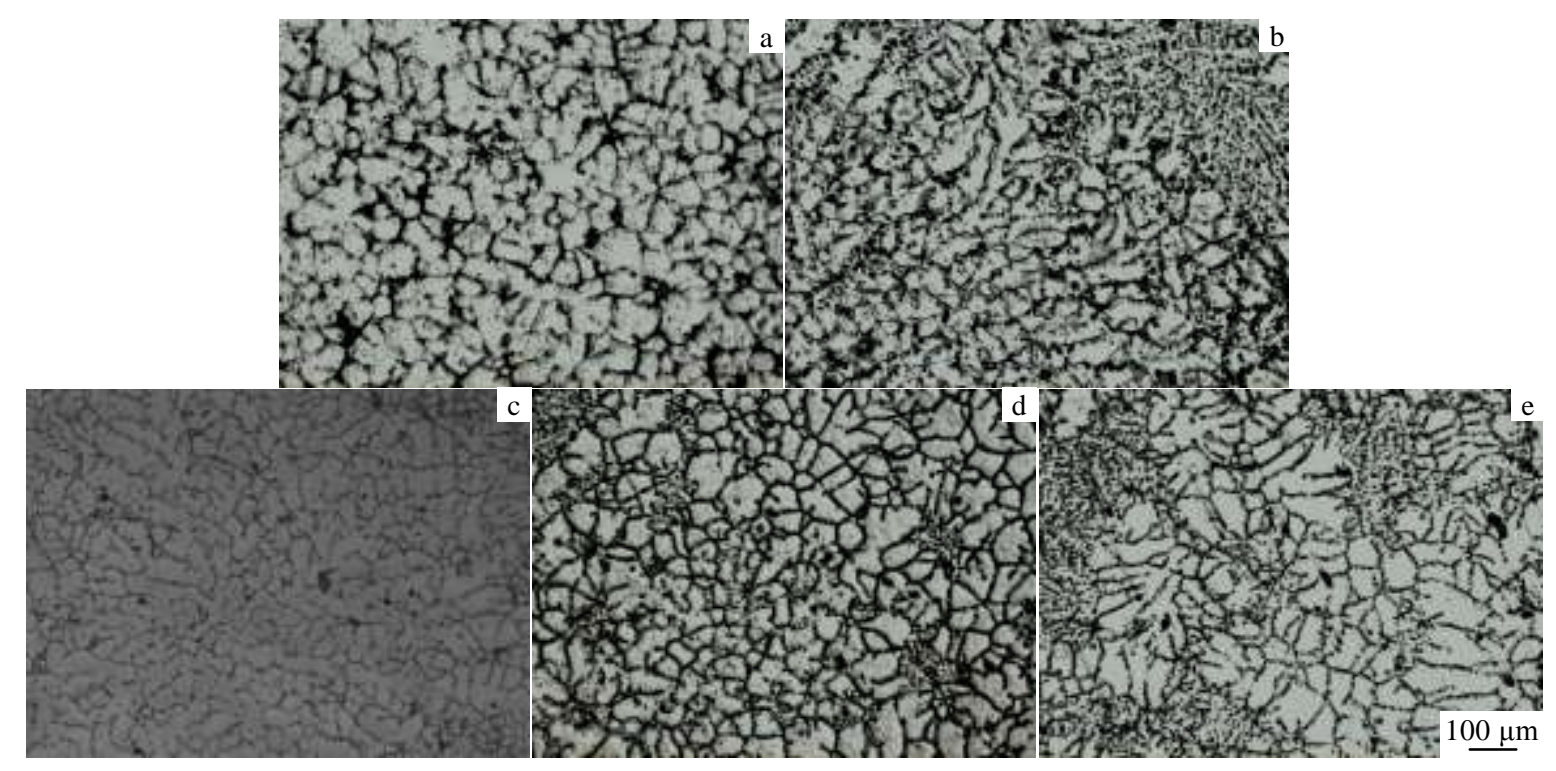

Fig.2 Microstructures of AZ91D magnesium matrix composites with different contents of quasicrystal master alloy: (a) 0\%, (b) 3\%, (c) $5 \%$, (d) $7 \%$, and (e) $10 \%$

To confirm the existence of quasicrystals, SEM, EDS and TEM observations were performed for the composite sample of $7 \%$ as shown in Fig.3. It can be seen clearly from Fig.3a that some new strengthening phase particles (A point) distribute in the composite besides $\alpha-\mathrm{Mg}$ matrix and $\beta-\mathrm{Mg}_{17} \mathrm{Al}_{12}$ around grain boundaries. The result of EDS indicates that the chemical composition of the particles is $\mathrm{Mg}_{32} \mathrm{Zn}_{55} \mathrm{Y}_{13}$ (Fig.3b) which is close to the standard I-phase of $\mathrm{Mg}_{3} \mathrm{Zn}_{6} \mathrm{Y}$. Fig. 3c presents bright-field images of I-phase and 5-fold symmetry of I-phase. The results firmly indicate that $\mathrm{Mg}_{3} \mathrm{Zn}_{6} \mathrm{Y}$ quasicrystal phase exists indeed with dispersive distribution in the composite. According to Fig.3a, it can also be found that the stable interface between quasicrystal particles and the $\alpha-\mathrm{Mg}$ matrix is formed and the growth of matrix grains is inhibited by the low interface energy of quasicrystals.

In this study, the smelting temperature is $700{ }^{\circ} \mathrm{C}$, which is higher than the melting point of $\mathrm{Mg}_{3} \mathrm{Zn}_{6} \mathrm{Y}$ quasicrystal phase $\left(630.5^{\circ} \mathrm{C}\right)$ as reported in Ref.[15]. So AZ91D alloy and $\mathrm{Mg}_{3} \mathrm{Zn}_{6} \mathrm{Y}$ quasicrystal particles both melt during the process of smelting. Then $\mathrm{Mg}_{3} \mathrm{Zn}_{6} \mathrm{Y}$ quasicrystal particles precipitate again from the melt during solidification after squeeze casting to strengthen AZ91D alloy. Hence, the preparation of the composites includes the addition of $\mathrm{Mg}-\mathrm{Zn}-\mathrm{Y}$ quasicrystal master alloy and the formation of in-situ $\mathrm{Mg}_{3} \mathrm{Zn}_{6} \mathrm{Y}$ quasicrystal particles during solidification.

\subsection{Tensile properties}

The tensile properties of squeeze casting AZ91D alloy and quasicrystal reinforced AZ91D magnesium matrix composites with different contents of quasicrystal master alloy are presented in Fig.4. It is shown that the ultimate tensile strength and elongation of the composites firstly increase and then decrease with increasing the content of quasicrystal master alloy. The addition of quasicrystal can significantly increase the tensile properties of AZ91D alloy when the content of quasicrystal master alloy is $5 \%$. Under
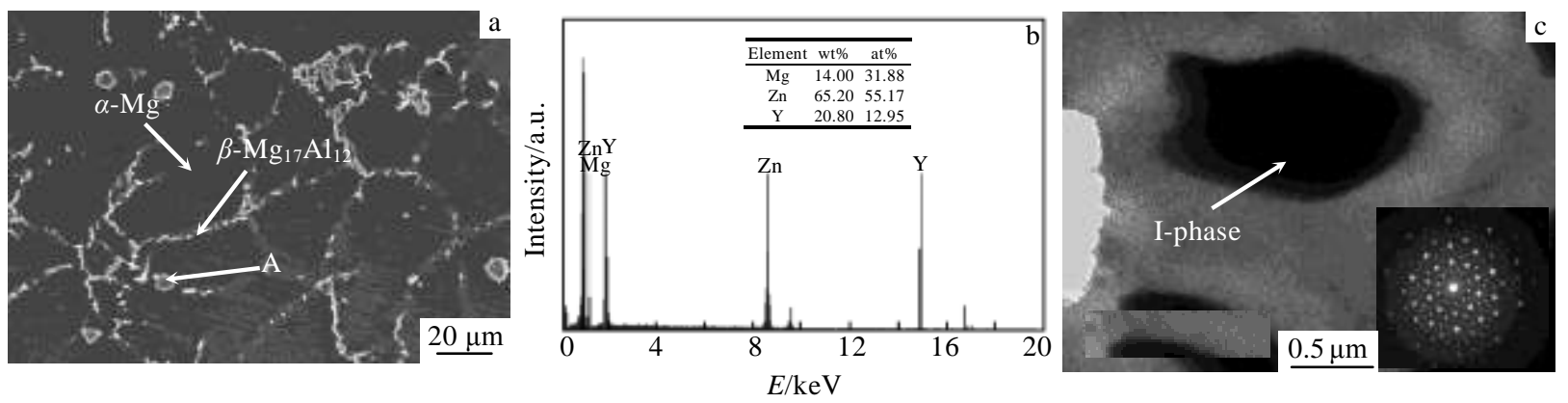

Fig.3 SEM image (a) and EDS result of point A (b); TEM bright-field image of I-phase and 5-fold symmetry of I-phase (c) for composite sample with $7 \%$ quasicrystal master alloy 


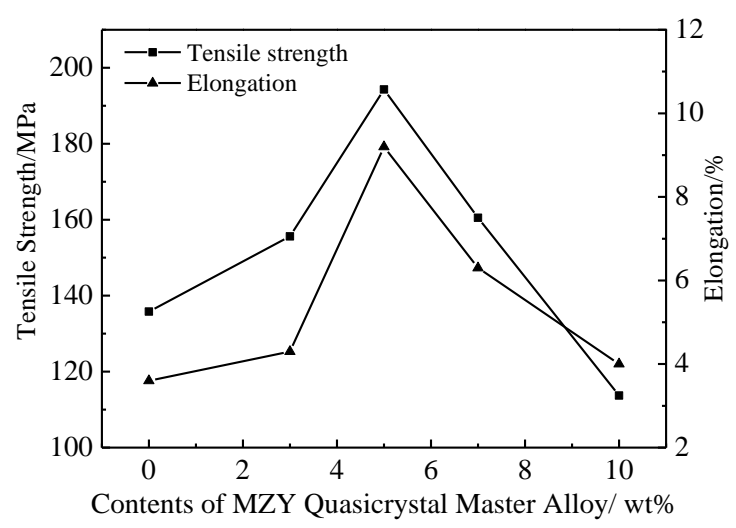

Fig.4 Influences of different quasicrystal master alloy contents on tensile properties of AZ91D magnesium matrix composites

such a condition, the ultimate tensile strength and elongation both reach the maximum values of $193.4 \mathrm{MPa}$ and $9.2 \%$, which are $43.1 \%$ and $155.6 \%$ higher than those of AZ91D alloy, respectively. Poor properties of AZ91D alloy are due to coarse microstructure. The reasons for properties improvement lie in the fine-grain strengthening effect and quasicrystal particles strengthening effect. However, an obvious Bi-modal structure is formed to produce stress concentration, which contributes to the reduction of tensile properties with further increasing the content of quasicrystal master alloy to $7 \%$ and $10 \%$. Moreover, when the content of quasicrystal master alloy is excessive, brittle quasicrystal particles distribute in the vicinity of grain boundaries to reduce tensile properties.

\subsection{Fracture behavior}

The SEM images of tensile fracture for the composites with different contents of quasicrystal master alloy are displayed in Fig.5. We can see that the fracture surface of AZ91D alloy (Fig.5a) shows a typical cleavage river pattern with tearing ridge and cleavage steps, which is consistent with the result of elongation. The observed fracture mode of the composite with $3 \%$ quasicrystal master alloy is quasi-cleavage fracture with tearing ridges and a small quantity of dimples (Fig.5b). As the content of quasicrystal master alloy increases to $5 \%$ and $7 \%$, more deeper equalaxis dimples and tearing ridges occur during the tensile test (Fig.5c and 5d). It can also be found that quasicrystal particles homogenously distribute on the fracture surfaces to make slip proceed easily. When $10 \%$ quasicrystal master alloy is added into AZ91D alloy, the fracture surface tends to be smooth and presents a typical brittle rupture (Fig.5e). This is related to stress concentration caused by non-homogenous distribution of microstructure which results in crack initiation and propagation. The SEM observations of the fracture surfaces are in good agreement with the tensile behavior of the composites.

\subsection{Strengthening mechanism analysis}

Fine-grain strengthening is mainly realized by changing grain size of magnesium alloys. Grain boundaries can effectively inhibit dislocation gliding to improve properties. Meanwhile, stress concentrations in front of the grain boundaries activate more slip systems to make uniform deformation and to improve the toughness of alloys. The smaller the grain size, the larger the grain boundaries to enhance the strengthening effect. In this paper, the squeeze casting process is an effective method to increase cooling rate and achieve grain refinement. Besides, $\mathrm{Mg}_{3} \mathrm{Zn}_{6} \mathrm{Y}$ quasicrystal particles can effectively prevent grain growth to exhibit the grain refinement effect.

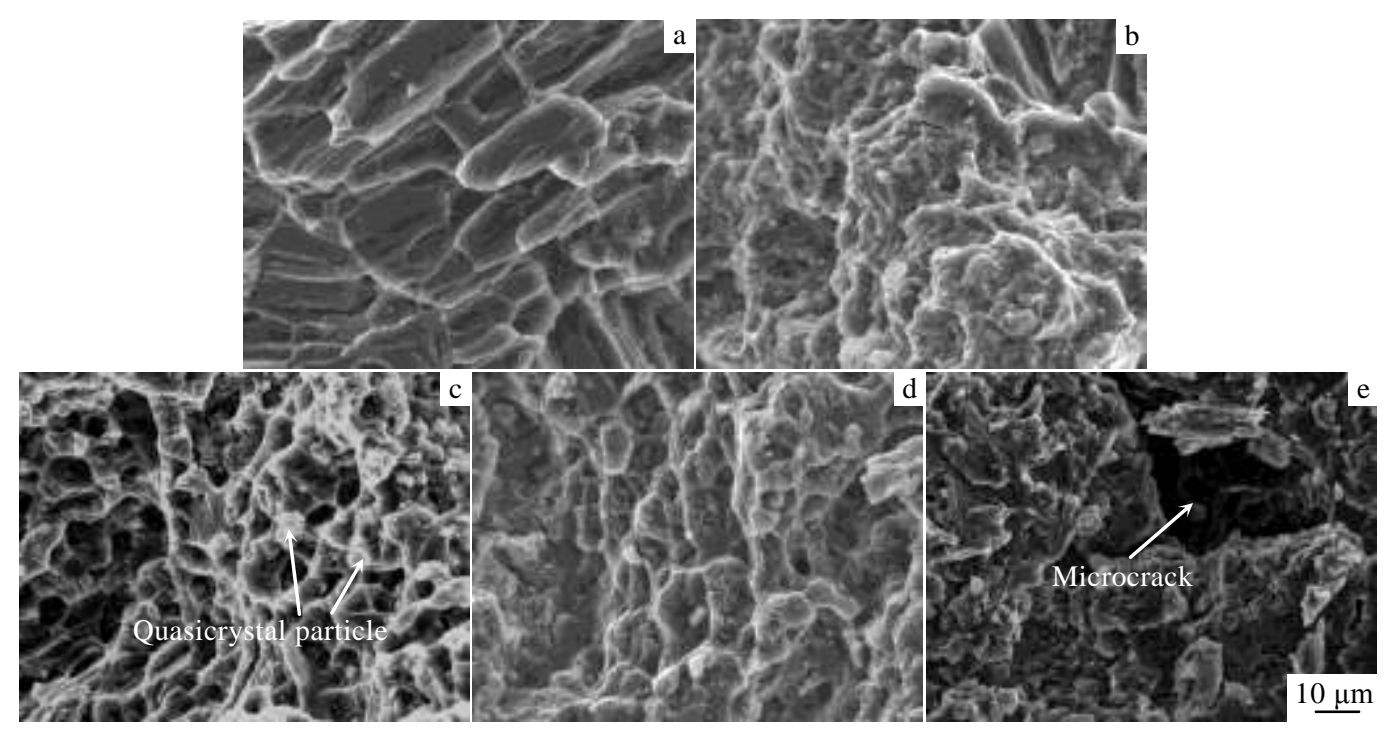

Fig.5 SEM images of tensile fracture for composites with different contents of quasicrystal master alloy: (a) $0 \%$, (b) $3 \%$, (c) $5 \%$, (d) $7 \%$, and (e) $10 \%$ 
As reinforcing phase, quasicrytal particles with smaller sizes are distributed homogeneously in $\alpha-\mathrm{Mg}$ matrix or around $\beta-\mathrm{Mg}_{17} \mathrm{Al}_{12}$ phase. Due to low surface energy of quasicrystals as well as similarity between quasicrystal particles and the matrix, excellent wettability between them can be obtained. Hence, quasicrystal particles have less rending effect on the matrix and the stress concentration degree in the matrix is much low. $\operatorname{Mg}_{3} \mathrm{Zn}_{6} \mathrm{Y}$ quasicrystal particles prevent the diffusion of $\mathrm{Al}$ and $\mathrm{Zn}$ elements, which results in fine grain size of the matrix. It can be observed from Fig.5 that there is no interfacial reaction between the $\mathrm{Mg}_{3} \mathrm{Zn}_{6} \mathrm{Y}$ quasicrystal particles and the $\alpha-\mathrm{Mg}$ matrix; meanwhile, there is no brittle phase existing at the interface by providing high interface bonding properties. $\mathrm{Mg}_{3} \mathrm{Zn}_{6} \mathrm{Y}$ quasicrystal particles can effectively pin the grain boundaries and prevent the migration of $\beta-\mathrm{Mg}_{17} \mathrm{Al}_{12}$ phase at grain boundaries. For these composites, the load is mainly undertaken by $\alpha-\mathrm{Mg}$ matrix and partly borne by high hardness of quasicrystal particles. The dispersively distributed quasicrystal particles can restrain the matrix deformation under stress, prevent dislocation movement, exhibit the dispersion strengthening effects and finally improve the strength of AZ91D alloy.

\section{Conclusions}

1) The microstructures of AZ91D composites with different contents of quasicrystal master alloy mainly consist of $\alpha$-Mg matrix, $\beta$ - $\mathrm{Mg}_{17} \mathrm{Al}_{12}$ phase surrounding the boundaries and $\mathrm{Mg}_{3} \mathrm{Zn}_{6} \mathrm{Y}$ icosahedral quasicrystal particles.

2) The ultimate tensile strength and elongation of composites firstly increase and then decrease with increasing the content of quasicrystal master alloy. When the content of quasicrystal master alloy is $5 \%$, the ultimate tensile strength and elongation of the composite reach the maximum values of $193.4 \mathrm{MPa}$ and $9.2 \%$, which are $43.1 \%$ and $155.6 \%$ higher than AZ91D alloy respectively. Tensile fractographs for composites indicate that the fracture modes of the squeeze casting composites transit from brittle cleavage to quasi-cleavage with increasing the content of quasicrystal master alloy.

3) The strengthening mechanisms are considered as finegrain strengthening and quasicrystals particles strengthening.

\section{References}

1 Deng $\mathrm{K} \mathrm{K}, \mathrm{Wu} \mathrm{K}, \mathrm{Wu} \mathrm{Y}$ W et al. Journal of Alloys and Compounds[J], 2010, 504: 542

2 Nie K B, Wang X J, Hu X S et al. Materials Science and Engineering $A[\mathrm{~J}], 2011,528: 5278$

3 Cao Wei, Zhang Congfa, Fan Tongxiang et al. Materials Science and Engineering A[J], 2008, 496: 242

4 Wan Diqing, Yang Gencang, Zhu Man et al. Transactions of Nonferrous Metals Society of China[J], 2007, 17(3): 586

5 Zhang Jinshan, Du Hongwei, Lu Binfeng et al. Transactions of Nonferrous Metals Society of China[J], 2007, 17(2): 273

6 Zhao Zhenwei, Teng Xinying, Zhou Guorong et al. Rare Metal Materials and Engineering [J], 2014, 43(4): 791 (in Chinese)

7 Kim B, Do J, Lee S et al. Materials Science and Engineering $A[\mathrm{~J}], 2010,527(24-25): 6745$

8 Do J, Kim B, Park Y et al. Metallurgical and Materials Transactions A[J], 2012, 43(8): 2955

9 Zhou Ming, Hu Henry, Li Naiyi et al. Journal of Materials Engineering and Performance[J], 2005, 14(4): 539

10 Zheng Mingyi, Wu Kun, Yao Congkai et al. Journal of Materials Science Letters[J], 2002, 21(7): 533

11 Zheng Mingyi, Wu Kun, Li Subo et al. Journal of Materials Science Letters[J], 2001, 20(16): 1501

12 Yong M S, Clegg A J. Journal of Materials Processing Technology[J], 2005, 168(2): 262

13 Hashemi H R, Ashoori H, Davami. Materials Science and Technology[J], 2001, 6(17): 639

14 Reddy G S, Sekhar J A. Acta Metallurgica[J], 1989, 37(5): 1509

15 Gröbner J, Kozlov A, Fang X Y et al. Acta Materialia[J], 2012, 60(17): 5948

\title{
挤压铸造准晶增强 AZ91D 镁基复合材料组织与性能
}

\author{
杨 玲, 侯 华, 赵宇宏, 杨晓敏 \\ (中北大学，山西 太原 030051)
}

\begin{abstract}
摘 要: 为了改善AZ91D镁合金的性能, 采用挤压铸造法制备了Mg-Zn-Y准晶中间合金增强AZ91D镁基复合材料, 研究了准晶中间合金 含量对复合材料组织和性能的影响。结果表明挤压铸造工艺可以有效细化晶粒, 复合材料的显微组织主要由 $\alpha-\mathrm{Mg}$ 基体、晶界上分布的 $\beta-\mathrm{Mg}_{17} \mathrm{Al}_{12}$ 相以及 $\mathrm{Mg}_{3} \mathrm{Zn}_{6} \mathrm{Y}$ 准晶颗粒组成, 准晶颗粒和 $\alpha-\mathrm{Mg}$ 基体之间形成稳定结合。当准晶中间合金含量为 $5 \%$ 时, 抗拉强度和断后伸长 率达到最大值, 分别为 $194.3 \mathrm{MPa}$ 和 $9.2 \%$ 。复合材料的强化机制为细晶强化和准晶颗粒强化。

关键词：镁基复合材料；挤压铸造；准晶；显微组织；力学性能
\end{abstract}

作者简介: 杨 玲, 女, 1981 年生, 博士, 讲师, 中北大学材料科学与工程学院, 山西 太原 030051, 电话: 0351-3945988, E-mail: yangling19810128@163.com 